\title{
Avaliação do papel dos telhados verdes no desenho e desenvolvimento urbano de baixo impacto ambiental e no controle de enchentes na Cidade do Rio de Janeiro
}

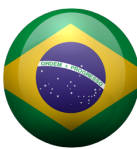 \\ Dayana Martins Nunes \\ Mestranda em Engenharia Ambiental pela Universidade do Estado do Rio de Janeiro - PEAMB/UERJ. Rio de \\ Janeiro [RJ] Brasil <dayana.mnunes@gmail.com>.

\section{Paulo Luiz da Fonseca} \\ Professor Adjunto do Departamento de Engenharia Civil, Universidade Federal Fluminense. Niterói [RJ] \\ Brasil < paulofonseca@vm.uff.br>.

\section{Luciene Pimentel da Silva} \\ Professora Associada do Departamento de Engenharia Sanitária e do Meio Ambiente, Universidade do \\ Estado do Rio de Janeiro. Rio de Janeiro [RJ] Brasil <luciene.pimenteldasilva@gmail.com>.
}

\section{Resumo}

Este trabalho discute o papel dos telhados verdes no desenho e desenvolvimento urbano de baixo impacto ambiental. São aprofundadas as questões relacionadas ao manejo das águas pluviais urbanas e é avaliado o desempenho dos telhados verdes como dispositivos nos sistemas de micro e macrodrenagem. A metodologia envolveu a aplicação de modelos computacionais hidrológicos-hidráulicos através de estudo de caso em bacia hidrográfica localizada em área de paisagem periurbana na cidade do Rio de Janeiro. 0 modelo computacional adotado, SWMM da US-EPA, permite que se insira de maneira hipotética estes dispositivos em edificações préexistentes. Através do estudo de cenários sem e com inserção de telhados verdes, pode-se avaliar virtualmente o papel destes dispositivos na redução dos volumes escoados superficialmente e da vazão instantânea máxima, assim como das condições de extravasamento da calha fluvial sob chuva intensa real observada no local em abril de 2010. Os resultados permitiram verificar que apesar de não reverter o extravasamento da calha fluvial, os telhados verdes tiveram impacto na redução dos volumes escoados superficialmente, que agravam as enchentes urbanas, e da vazão máxima instantânea em até $10 \%$ aproximadamente. A partir destes resultados e da avaliação das outras sinergias dos telhados verdes com o desenho e desenvolvimento urbano de baixo impacto ambiental recomenda-se o incentivo de políticas públicas que possam viabilizar sua adoção nas cidades Brasileiras com vistas à melhoria da qualidade de vida da população que habita os aglomerados urbanos.

\section{Palavras-chave}

Rede de Pesquisa FINEP - BRUM. DDUBI. Telhados Verdes. SWMM. Controle de Enchentes.

\section{Evaluation of the implantation of green roofs in urban basins to control surface runoff: a case study in the basin of the Morto river, Rio de Janeiro}

\begin{abstract}
This paper discusses the role of green roofs in the low impact urban design and development. The issues related to urban storm water management are deepened and the performance of green roofs is evaluated as devices in micro and macro drainage systems. The methodology involved the application of hydrologicalhydraulic computational models through a case study in a catchment located in peri-urban landscape area in the city of Rio de Janeiro. The adopted US-EPA SWMM model allows these devices to be hypothetically inserted into pre-existing buildings. Through the study of scenarios without and with insertion of green roofs, the role of these devices can be evaluated in the reduction of the volumes surface runoff and the maximum instantaneous stream flow, as well as of the conditions of river flow floods under real intense rain observed in April 2010. The results showed that, despite not reversing the river flow floods, the green roofs had an impact on the reduction of the volumes surface runoff, which aggravate urban floods, and the maximum instantaneous flow rate up to approximately $10 \%$. From these results and the evaluation of the other synergies of the green roofs with the low impact urban design and development, it is recommended the encouragement of public policies that can make its adoption feasible in the Brazilian cities with a view to improving the quality of life of the population that inhabits urban agglomerations.
\end{abstract}

\section{Keywords}

FINEP Research Network BRUM. LIUDD. Green Roofs. SWMM. Flooding Control. 


\section{Introdução}

O desenho e desenvolvimento das cidades de forma democrática com acesso equilibrado aos serviços de infraestrutura urbana e garantias de melhoria contínua da qualidade de vida tem se apresentado como um grande desafio, sobretudo nos países em desenvolvimento com seus problemas recorrentes sociais e econômicos. Como resultado, têm sido observadas áreas ambientalmente degradadas nos espaços urbanos e suas periferias, catalisadores de problemas de saúde pública, que atingem de maneira tendenciosa e injusta a qualidade de vida, sobretudo da população mais vulnerável de interesse social. Esta população sujeita às políticas insuficientes de oferta de habitação digna popular e sem recursos econômicos para arcar com os altos valores dos terrenos das áreas formais urbanizadas das cidades, acaba habitando as periferias dos aglomerados urbanos, os espaços vazios das cidades. Estes espaços estão geralmente associados às fragilidades ambientais como áreas de baixada e encostas de morros íngremes, cenário recorrente na Cidade do Rio de Janeiro. Embora a situação das ocupações subnormais seja emblemática no Rio de Janeiro, a mesma se repete em muitas cidades do litoral Brasileiro, onde as florestas de mata atlântica foram sendo desmatadas para dar lugar à ocupação e expansão dos aglomerados urbanos (Cerqueira \& Pimentel da Silva, 2013).

Esta problemática se dá em um contexto mais amplo, mundial, em que têm sido questionadas as políticas e formas de ocupação dos espaços urbanos e seus desdobramentos na qualidade de vida de seus habitantes. Na América Latina a taxa de urbanização média é da ordem de $76,14 \%$. No Brasil, mais de $80 \%$ da sua população reside em centros urbanos, enquanto em 1950 eram apenas 36,2\% (Ministério das Cidades, 2005). 0 crescimento da urbanização no Brasil tem sido caracterizado predominantemente pela expansão desordenada em direção às periferias. A Região da Bacia Hidrográfica de Jacarepaguá se insere neste modelo. Em paralelo aos loteamentos regulares, houve uma ocupação das áreas de baixada e várzeas de rios por parte da população de menor renda como alternativa ao déficit habitacional e à especulação imobiliária, dotando a região com índices de densidade de habitantes por hectare cada vez maiores. Este processo foi acentuado com o forte aparelhamento da região em função da realização dos Jogos Olímpicos em 2016.

0 processo de urbanização promove uma ruptura das condições de equilíbrio do meio ambiente, promovendo mudanças significativas, em especial nos recursos hídricos, mesmo em cidades do mundo desenvolvido, cujo desenvolvimento já se deu em contexto social e econômico mais favorável, e dentro dos princípios da sustentabilidade ambiental. Colabora neste sentido o cenário atual de mudanças climáticas e incertezas que vulnerabilizam as populações concentradas nos núcleos urbanos aos riscos de eventos naturais e desdobramentos dos impactos do desenvolvimento urbano e industrial, como efeitos das ilhas de calor, ventos fortes, raios, tempestades, movimentos de massa, deslizamentos de terra e enchentes.

Hall (1984) descreve de forma sistemática os impactos da urbanização no ciclo hidrológico e no desenvolvimento dos recursos hídricos. De fato, o aumento de construções e a redução das áreas verdes derivados do processo de urbanização, constituem um dos impactos mais significativos no ciclo hidrológico, reduzindo as taxas de infiltração das águas pluviais, o que por sua vez levam à diminuição das taxas de recarga para os aquíferos e à diminuição do escoamento básico. A diminuição do escoamento básico contribui para o aumento da extensão de rios com leitos secos nas áreas urbanas e periféricas. Os efeitos das ilhas de calor potencializam a ocorrência de chuvas intensas. 0 escoamento superficial é intensificado, aumentando em velocidade, em frequência e magnitude dos picos de cheia, levando à ocorrência de enchentes. Por outro lado, a disposição inadequada de resíduos sólidos, efluentes e esgotos, as ligações clandestinas de efluentes residenciais e industriais à rede pluvial e rios, o setor de transportes com a adição de hidrocarbonetos e ainda a presença de organismos patogênicos contribuem para a degradação da qualidade das águas em escoamento oriundas das chuvas. Ressalta-se que a degradação da qualidade das águas é uma forma de tornar indisponíveis os recursos hídricos, ainda que em disponibilidade quantitativa. Adicionalmente, devem ser considerados ainda os rebatimentos dos problemas de recursos hídricos na saúde coletiva.

Os projetos convencionais de drenagem das águas pluviais urbanas sempre vieram acompanhados do eventual redesenho, da retificação e canalização dos cursos d'água naturais. Estas intervenções estavam relacionadas com o conceito higienista da época, que tinha por objetivo afastar rapidamente 
as águas pluviais em excesso do local de origem, efluentes domésticos e industriais, usando muitas vezes a mesma rede hidráulica para esta finalidade. Esta estratégia mostrou-se muito efetiva por algum tempo, mas diante da dinâmica de desenvolvimento humano e urbano que viriam a ser observados e das mudanças climáticas que se sucederam, levaram a alguns rebatimentos indesejáveis no meio urbano, como a degradação ambiental em várias áreas das cidades e dos corpos hídricos receptores dos excessos pluviais.

Neste contexto, as demandas oriundas destes diversos setores na perspectiva da sustentabilidade da matriz hídrica urbana colocam a articulação do planejamento urbano, o planejamento e a gestão integrada dos recursos hídricos no centro do debate atual. Tais questões demandam a busca por soluções que não se limitam ao campo restrito de uma disciplina ou das análises isoladas. Esta nova visão integrada teve início na década de 1980 nos Estados Unidos, sendo conhecida como Best Management Practices (BMPS) - Melhores Práticas de Gestão, que corresponde ao conjunto planejado de ações na bacia hidrográfica buscando a garantia da disponibilidade e qualidade das águas pluviais (AMEC, 2001). Observa-se a evolução das BMP's para o Desenho e Desenvolvimento Urbano de Baixo Impacto Ambiental (DDUBI) que tem sido proposto e aplicado em vários países e cidades do mundo, com vistas a reconduzir as cidades e aglomerados urbanos aos caminhos da sustentabilidade, contribuindo no sentido de aumentar a resiliência desses espaços aos impactos das mudanças climáticas e seus desdobramentos. O DDUBI é uma proposta mais abrangente e envolve as práticas da gestão participativa, diminuição da queima de combustíveis fósseis com a melhoria da mobilidade urbana, geração de emprego e renda em escala local. Além disso, conta com uma série de infraestruturas verdes (Krüger \& Dziedzic, 2010; Rossi \& Sousa, 2012).

Neste contexto, este trabalho discute o papel dos telhados verdes como medida transversal no DDUBI, aprofundando a discussão sobre os possíveis impactos no controle das enchentes urbanas, se inseridos nas edificações de forma mais ampla nos espaços urbanos. Neste sentido, a aplicação de modelo computacional hidrológico-hidráulico permite a avaliação do impacto que os telhados verdes poderiam exercer no controle das enchentes, em áreas mais abrangentes e consolidadas no espaço territorial da bacia hidrográfica.

Toma-se como objeto de estudo uma bacia hidrográfica representativa na Baixada de Jacarepaguá, região de expansão da Cidade do Rio de Janeiro, e que tem sido fortemente impactada de um lado pelo aparelhamento para realização dos jogos olímpicos em 2016, e por outro pela especulação imobiliária e ampliação de espaços subnormais, que acabam ampliando as superfícies impermeáveis, podendo agravar as enchentes urbanas que já são recorrentes no local. São analisados os resultados com base em simulações computacionais de cenários com inserção de telhados verdes de forma ampla na bacia hidrográfica, representativa do objeto do estudo. Foi aplicado o modelo hidrológicohidráulico SWMM da US-EPA (Agência Americana de Proteção Ambiental), que permite a cenarização da adoção de telhados verdes em edificações existentes, avaliando o potencial da adoção dos telhados verdes na redução das velocidades de escoamento, das vazões máximas e dos volumes escoados, indicadores essenciais nas questões associadas à ocorrência de enchentes urbanas. A avaliação é feita com base na comparação desses elementos no estágio atual de uso e ocupação do solo e após a inserção de telhados verdes em edificações existentes. Para as simulações foi adotado um evento pluviométrico de longa duração e de alta intensidade que ocorreu na Região em Abril de 2010, e causou transbordamento de rios, desmoronamentos de residências alocadas próximas às margens dos cursos d'água, deixando vários desabrigados e desalojados, comprometendo o acesso às vias importantes na região, pela duração de mais de três dias das inundações. Este trabalho faz parte das iniciativas do Projeto de Pesquisa e Extensão HIDROCIDADES (Pimentel da Silva et al., 2008), que vem integrando a Rede de Pesquisa MCT/ FINEP de Bacias Representativas de Uso Misto (BRUM).

\section{Desenho e Desenvolvimento Urbano de Baixo Impacto Ambiental}

DDUBI adaptado da sigla em inglês LIUDD - Low Impact Urban Design and Development - e Desenvolvimento de Baixo Impacto ou LID - Low Impact Development - são termos usualmente adotados na Nova Zelândia e nos Estados Unidos para denotar um conjunto de práticas para o desenho e desenvolvimento de áreas urbanas. Fletcher et al. (2014) menciona que o termo aparentemente foi utilizado pela primeira vez por Barlow et al. (1977) em um relatório sobre planejamento do uso do solo em Vermont nos Estados Unidos. A abordagem era minimizar os custos na gestão das águas 
pluviais através de desenho urbano segundo uma abordagem naturalista. A abordagem inicial do LID era promover a naturalização do ciclo hidrológico utilizando o layout local e medidas de controle integradas. A naturalização do ciclo hidrológico envolve a busca por promover as condições prévias às intervenções urbanísticas e as medidas de controle geralmente consistem em dispositivos que promovem infiltração, armazenamento e evapotranspiração, restaurando os volumes prévios que ocorriam na bacia hidrográfica e valorizando a paisagem e os ecossistemas naturais. 0 LID desincentiva as práticas convencionais de drenagem que via de regra visam o controle dos excessos pluviais nos sistemas de drenagem de jusante, retificação de rios, transformando-os em canais de drenagem, promovendo a aceleração e condução rápida dos escoamentos pluviais para jusante. Esta estratégia se mostra efetiva até certo ponto, mas implica em ampliações frequentes do sistema de drenagem, conforme crescimento da população, da impermeabilização das superfícies e mudanças nas dinâmicas das chuvas locais. Além dos elevados custos, esta proposta, também denominada de higienista (Baptista et al., 2005), implica em operação onerosa do sistema de drenagem e transtornos na mobilidade dos centros urbanos, já que as redes de drenagem implicam em tubulações enterradas. Além disso, nos sistemas de drenagem convencionais, as águas pluviais em excesso são entendidas como um transtorno e não visam, em princípio, o controle da qualidade das águas em escoamento e da degradação dos corpos hídricos receptores.

DDUBI caracteriza-se como uma nova estratégia para o desenvolvimento urbano dentro das perspectivas do desenvolvimento sustentável, e está dentro da trajetória evolutiva das chamadas Best Management Practices ou BMPs (Poleto, 2011). Fletcher et al. (2014) apresentaram uma discussão dos diferentes jargões que têm sido usados na atualidade para caracterizar as diferentes iniciativas para o desenvolvimento urbano sustentável em diferentes nações do mundo a fim de documentar a história recente e a evolução das terminologias em drenagem urbana: Low Impact Design - LID (Coffman, 2002), Water Sensitive Urban Design - WSUD (Lloyd, 2003), Sustainable Urban Drainage System - SUDS (Chatfield, 2005) e Low Impact Urban Design and Devolopment - LIUDD (Van Roon \& Van Roon, 2005; Van Roon, 2006).

A evolução do DDUBI pode ser vista como um modelo de governança para as águas pluviais onde as mesmas são valorizadas enquanto recurso natural e tomadas como fio condutor nas propostas de desenho articulado e integrado ao desenvolvimento da infraestrutura urbana e dos recursos hídricos. A evolução do DDUBI se dá pelos caminhos dos processos participativos, incentivados em diferentes níveis, envolvendo políticas de disseminação de hábitos pessoais capazes de diminuir a pressão sobre a água enquanto recurso natural (Van Roon, 2006).

O DDUBI vai além das questões de drenagem, já que envolve aspectos holísticos sobre os ecossistemas, questões sociais e culturais, perpassando pela política e pela estrutura para gestão pública desses sistemas, geração de trabalho e renda em um novo contexto, e descentralização dos serviços de infraestrutura urbana - buscando a solução local das questões. Visa também preservar a água e a mitigação de vários outros aspectos dos impactos da urbanização. As medidas de controle com foco na água impactam de forma transversal outras questões. Cerqueira \& Pimentel da Silva (2016), ao proporem um framework para implementação do LIUDD em comunidades e áreas de ocupação subnormais em regiões peri-urbanas, destacaram os princípios que norteiam o LIUDD: 1) trabalho em consonância com a natureza, adotando a bacia hidrográfica como unidade de planejamento, mantendo a integridade dos sistemas e minimizando a pegada ecológica; 2) minimização dos impactos através da seleção de espaços adequados, com uso eficiente dos serviços que o próprio ecossistema pode proporcionar e maximização do uso dos recursos naturais locais, contendo e minimizando a geração de resíduos; 3) Estímulo às alternativas de desenvolvimento que restauram as condições naturais, aumentando a eficiência da infraestrutura. Na escala local, proposição da busca das condições pré-urbanização visando solo, água e ciclo de nutrientes. Otimização do reuso e/ou reciclagem, minimizando demandas e descargas externas. Integração da gestão das "três águas" (naturais e de abastecimento; servidas e de esgoto; e de drenagem) dentro dos limites da área de drenagem, em escala local. Redução e contenção de contaminantes. Proteção à população nativa, acompanhada da sensibilização quanto aos valores culturais, históricos e da biodiversidade (terrestre e aquática). Redução das necessidades de mobilidade (pessoas e materiais).

Entre os dispositivos inovadores do projeto de drenagem empregados no DDUBI (Figura 1) destacamse: trincheiras e poços de infiltração, caixas d'água e cisternas para armazenamento das águas pluviais, 


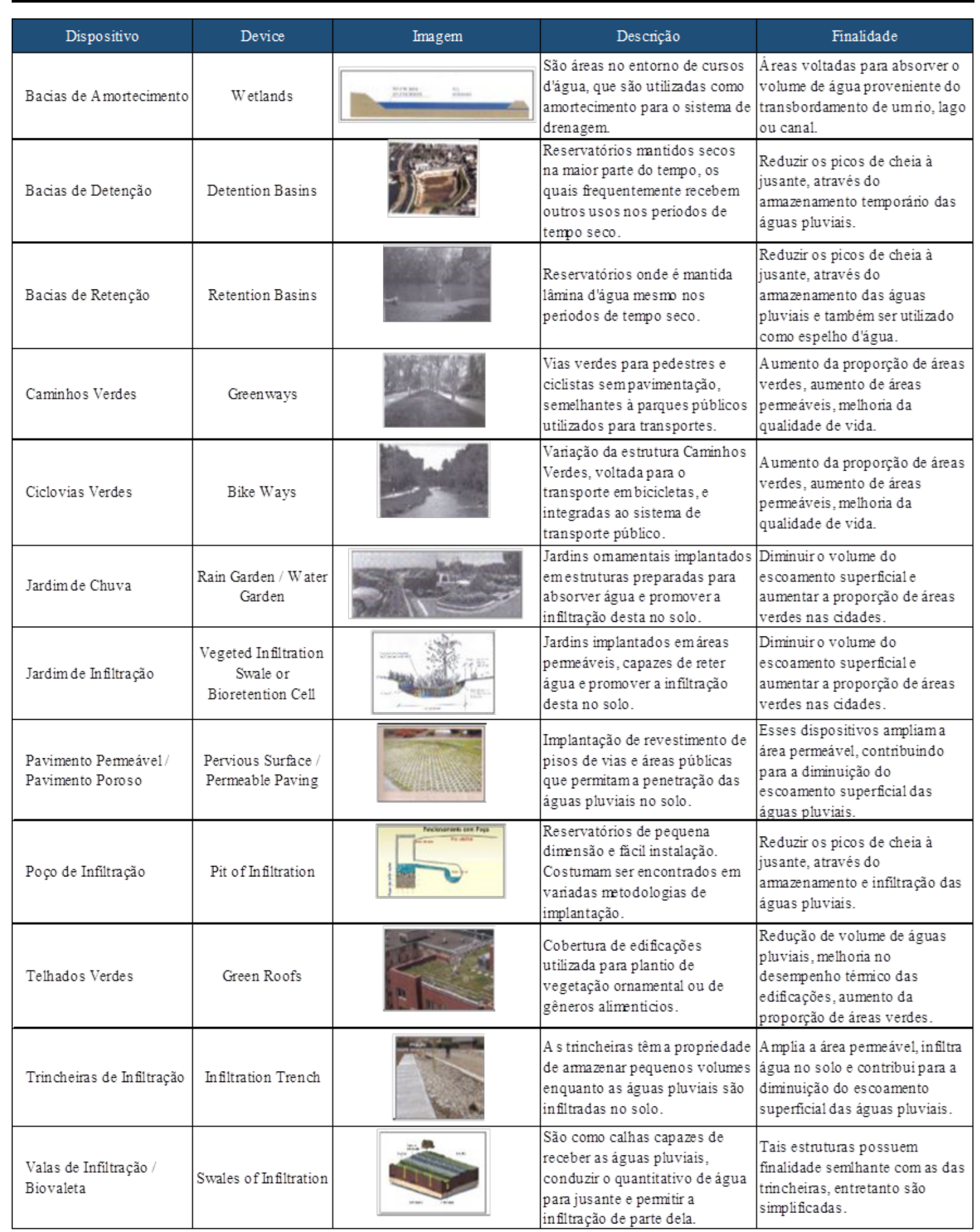

Figura 1. Consolidação das estruturas utilizadas nas metodologias de urbanismo de baixo impacto: LIUDD, LID, WSUD, e SUDS - português - inglês. Fonte: Cerqueira, 2012.

telhados verdes, valas de bioretenção, leitos de infiltração e evaporação, caixas de rolamento e passeios com pavimentos permeáveis, adoção de estruturas dentro das edificações que proporcionem a redução do consumo de água, proteção e restauração de "wetlands" dentro das cidades, tais como alagados, pântanos e manguezais (Bracey et al., 2008; Van Roon, 2012). Estes dispositivos estão consolidados com suas descrições e funções na Figura 1, a partir de Cerqueira (2012). Na Nova Zelândia, estes conceitos e práticas vinham evoluindo desde os fins da década de 1990 para que pudessem incorporar, além dos aspectos da abordagem LID, outros, com foco nos efeitos adversos como físico-químicos, biodiversidade, social, econômico, e amenidades da natureza, protegendo a 
integridade ecológica dos sistemas aquáticos, ainda que permitisse o desenvolvimento urbano em diferentes densidades ou intensidades. 0 LIUDD incorporou princípios ecológicos da chamada arquitetura verde, das experiências com eco vilas, "gestão integrada das três águas" (abastecimento, servidas e esgotos, drenagem) do WSUD, além do desenho de sistemas alternativos para gestão de águas servidas, dos conhecimentos sobre economia e meio ambiente, planejamento regional versus urbano, recuperação da paisagem e pesquisa no desenho, na implementação, operação e manutenção dos dispositivos e sistemas alternativos para gestão das águas pluviais. Destaca-se que o LIUDD foi proposto e tem norteado a urbanização de áreas peri-urbanas na Nova Zelândia, muitas ocupadas por grupos associados ao povo Maori, e ainda pouco impactadas, onde se percebeu um foco centrado no respeito e na preservação dos nativos e da biodiversidade. Há também referência clara aos processos participativos de tomada de decisão envolvendo políticas de disseminação de hábitos pessoais que possam diminuir a pressão sobre a água enquanto recurso natural (Van Roon, 2006).

\section{Telhados verdes como medida transversal no DDUBI}

Os telhados verdes consistem em técnica construtiva que envolve a implantação de vegetação sobre as coberturas das edificações. São também referenciados como telhados vivos, biocoberturas e ecotelhados. A Figura 2 apresenta as camadas construtivas estruturantes clássicas dos telhados verdes. As camadas de impermeabilização e de proteção se sobrepõem à superfície da cobertura e impedem que a umidade e as raízes interfiram na estrutura da cobertura e com o ambiente interno da edificação. A camada de substrato tem a função de nutrir e sustentar a vegetação. A camada de filtragem impede que os sedimentos junto aos fluxos de percolação possam aderir e prejudicar a drenagem.

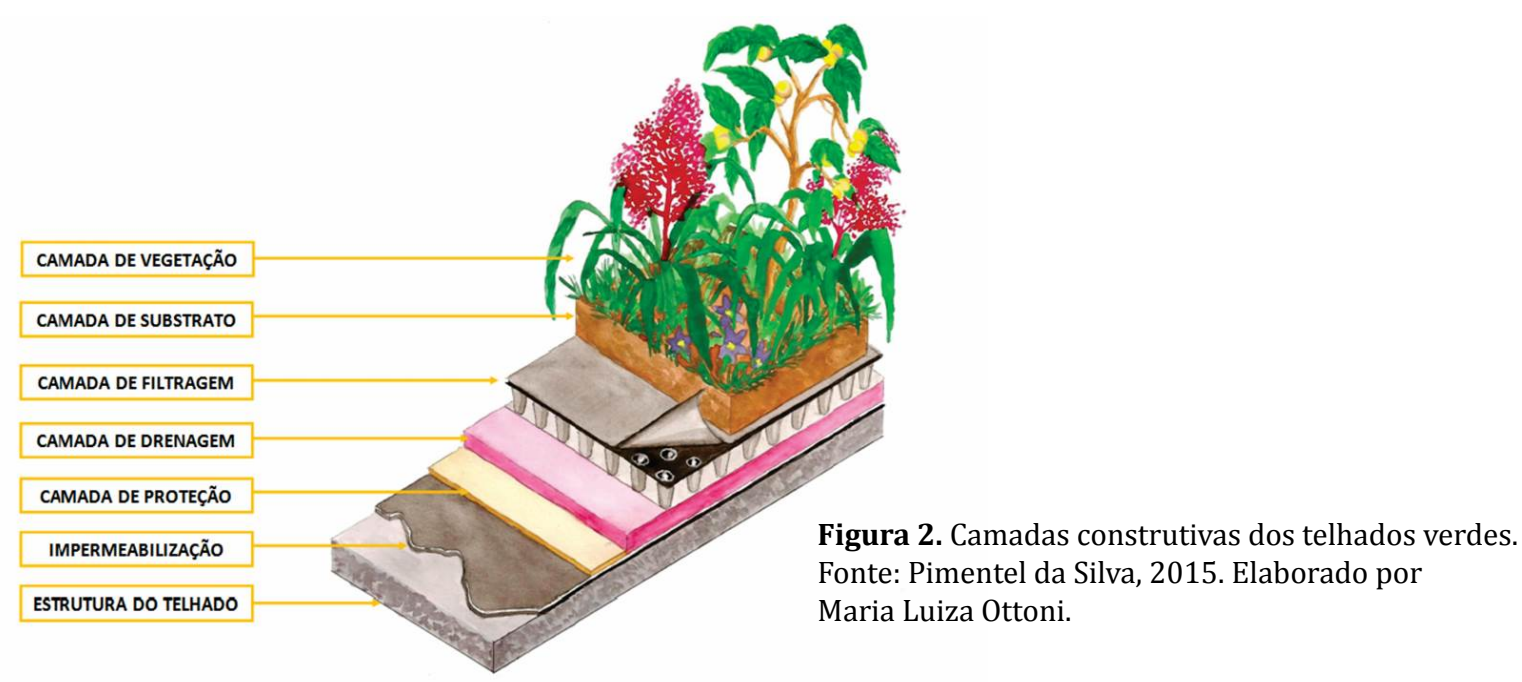

Nos telhados extensivos são utilizadas vegetações rasteiras, como ervas e gramíneas, e apresentam uma camada fina de substrato, baixo peso estrutural, baixa manutenção, reduzido consumo de água e possibilidade de construção sobre superfícies inclinadas. Já os telhados intensivos, são projetados com base na paisagem natural e, por isso, as gramas, flores, árvores e arbustos são os principais constituintes da vegetação. Assim, apresentam maior peso estrutural, possibilidade de maior retenção de água e utilização do espaço como recreação, embora exija maior manutenção (Getter \& Rowe, 2006; Carter \& Butler, 2008).

No DDUBI, os telhados verdes podem desempenhar múltiplos papéis gerando vários benefícios à população e ao meio ambiente, por isso são considerados como medidas transversais. Entre as funções dos telhados verdes, destacam-se seus impactos nas questões climáticas dos ambientes externos e internos das edificações com rebatimentos no consumo de energia para climatização dos ambientes internos e nas trocas de energia dessas superfícies com a atmosfera. Bianchini \& Hewage (2012) descrevem que a vegetação pode interferir no microclima por meio de sombreamento e da evapotranspiração, que converte a água do solo e das folhas em vapor d'água e em umidade, favorecendo assim a redução da temperatura do entorno. A interceptação da radiação solar pelas folhas reduz a transmissão do calor para as superfícies abaixo. Os telhados verdes podem contribuir na mitigação dos efeitos das ilhas de calor e no aquecimento global. Contribuem ainda para melhoria da qualidade do ar e redução dos ruídos. 
Oliveira (2009) desenvolveu um experimento na Região de Jacarepaguá na Cidade do Rio de Janeiro em que monitorou a temperatura interna de dois ambientes contíguos com isolamento térmico com filme aluminizado, e apenas um dos ambientes recebeu tratamento com telhados verdes. Observou diferenças de temperatura entre os dois ambientes de até $4{ }^{\circ} \mathrm{C}$ nos dias mais quentes no verão.

Os benefícios na redução do consumo de energia variam de acordo com o clima local, orientação geográfica, vento, características do projeto do telhado verde (tipo de vegetação, espessura e características do substrato agrícola e camadas subjacentes) e da construção. No verão os telhados verdes reduzem o fluxo de calor a partir do sombreamento e da evapotranspiração, aumentando o isolamento e a massa térmica (Berardi, Ghaffarianhoseini, \& Ghaffarianhoseini, 2014).

Áreas urbanas podem apresentar altos níveis de ruídos, que têm possíveis consequências físicas e psicológicas para os indivíduos. Stress, hipertensão, insônia, deficiência auditiva, distúrbio do sono são alguns dos problemas (Rowe, 2011; Rosseti et al., 2013). Áreas próximas de aeroportos, indústrias e ruas com edifícios altos, que formam corredores, apresentam condições mais graves com relação aos níveis de ruídos. Os telhados verdes podem reduzir a reflexão do som em até 3 dB e melhorar o isolamento acústico em até $8 \mathrm{~dB}$ (Rosseti et al., 2013). Mas, o nível de redução de ruído dependerá da geometria da construção, da distância da fonte geradora de ruídos e da espessura de substrato.

Os telhados verdes têm impacto positivo no controle da poluição do ar, já que a vegetação pode remover material particulado do ar (Rowe, 2011). Também impactam no paisagismo e podem trazer benefícios psicológicos. Podem contribuir para a restituição do ecossistema e do habitat natural. Estudos têm documentado a presença de pássaros e de insetos após implementação de telhados verdes (Canero \& Redondo, 2010).

Mas, outro impacto positivo determinante dos telhados verdes é com relação aos sistemas de microdrenagem, na escala de sub-bacias, já que promovem a retenção de águas pluviais, e em algumas configurações, podem ser usados materiais e substratos agrícolas que contribuem também no controle da poluição difusa, absorvendo algumas substâncias ou filtrando os efluentes. Os volumes retidos irão depender das características do projeto, inclinação da cobertura, do tipo de vegetação, das características físico-hídricas dos substratos e do estado de umidade do mesmo antes da precipitação. Também dependerá das características da precipitação pluviométrica e da evapotranspiração, também influenciada pelo tipo de vegetação e características do substrato (Bianchini \& Hewage, 2012).

Oliveira et al. (2009) realizaram alguns testes com vistas a verificar o potencial de estabelecimento de telhados verdes e o impacto dos mesmos na retenção das águas pluviais em edificações simples de um pavimento. A edificação utilizada, localizada na Escola Professor Teófilo Moreira da Costa em Vargem Grande, Baixada de Jacarepaguá, na Cidade do Rio de Janeiro, era pré-existente, em alvenaria, com dimensões de 6,0 x 4,0 metros de área, porém a área do telhado (cobertura) com 7,0 x 4,5 metros, pé direito de 3,20 metros, com cobertura de telhas onduladas de fibrocimento (onduline de $6 \mathrm{~mm}$ ), inclinação de $6 \%$, sem laje. No passado, a edificação funcionava como vestiários masculino e feminino, separados por uma parede, de forma que os ambientes eram simétricos. 0 telhado, após pequeno reforço estrutural com caibros de madeira, foi dividido em duas partes e apenas uma delas recebeu tratamento com telhados verdes. Foram instalados sistemas de irrigação por aspersão e de drenagem, independentes, em ambos os lados. Os ensaios foram realizados após a cobertura de apenas um dos lados com substrato agrícola comercial. 0 sistema de irrigação por aspersão foi utilizado para simular chuvas. Para uma intensidade de $42 \mathrm{~mm} / \mathrm{h}$, em ambos os lados, induzidos de forma simultânea, foi observado que a cobertura com telhados verdes foi capaz de reter $56 \%$ do volume total de água induzido. Enquanto o runoff do lado da cobertura sem tratamento de telhados verdes foi observado após 5 minutos do início da simulação da chuva, no lado com cobertura de telhados verdes só ocorreu após 11 minutos.

Berndtsson (2010) em um estudo comparativo entre substrato sem vegetação e com diferentes tipos de vegetação demonstrou que a retenção de água foi significativamente mais eficiente no verão do que no inverno, também observou que o tipo de substrato e sua espessura são fatoreschaves na redução do escoamento, e que a vegetação não é o principal fator de influência. No entanto, plantas suculentas possuem baixos níveis de evapotranspiração e boa cobertura da superfície 
do solo depois de desenvolvidas, o que acaba favorecendo a manutenção dos níveis de umidade do solo por mais tempo, sobretudo depois de chuvas intensas. No longo prazo, a capacidade de retenção dos solos pode ser diminuída.

Loiola et al. (2015) discute a retenção hídrica em telhados verdes. A partir da revisão da literatura, observou percentuais variados de retenção hídrica nos relatos sobre resultados de experimentos, entre $20 \%$ até pouco mais de $50 \%$. Poucos estudos apresentam retenções maiores do que $55 \%$.

Os telhados verdes podem agregar também benefícios ainda mais amplos, quando usados para o desenvolvimento da agricultura urbana. Neste contexto, contribuem entre outros, com a aproximação entre consumidor e produtor, na redução do consumo de combustíveis fósseis e emissão de $\mathrm{CO}_{2}$, no controle de preços e inflação no preço de alguns alimentos, aumento da segurança alimentar, além de geração de trabalho e renda (Pimentel da Silva et al., 2008; Mary et al., 2008; 2010).

\section{Linhas metodológicas para simulação computacional do impacto da inserção de telhados verdes no controle das enchentes urbanas}

\subsection{Caracterização da área de estudo}

A população da Região Hidrográfica da Baixada de Jacarepaguá é superior a 650.000 habitantes. Abrange os bairros da Região Administrativa (RA) XVI - Jacarepaguá: Jacarepaguá (mesmo nome da RA), Anil, Gardênia Azul, Cidade de Deus, Curicica, Freguesia, Pechincha, Taquara, Praça Seca e Tanque; e da Região Administrativa XXIV - Barra da Tijuca: Joá; Barra da Tijuca (mesmo nome da RA); Itanhangá; Camorim; Vargem Grande; Vargem Pequena; Recreio e Grumari.

A área total da Região Hidrográfica da Baixada de Jacarepaguá é de $301,40 \mathrm{~km}^{2}$, dos quais cerca de $120 \mathrm{~km}^{2}$ estão abaixo da cota $100 \mathrm{~m}$, constituindo então a referida baixada onde se encontram três lagunas principais: Tijuca, Jacarepaguá e Marapendi (Rosa, 2002). Estas estão dispostas paralelas às praias da Barra da Tijuca e Recreio dos Bandeirantes. Vários cursos d'água são originados nos maciços que cercam a baixada, desaguando principalmente nas lagoas que se comunicam com o mar. No extremo oeste da bacia existe uma rede de drenagem na forma de espinha de peixe que é formada pelo canal da Sernambetiba (Rio Morto que foi retificado) e canais secundários. A baixada de Jacarepaguá é bastante susceptível às inundações, sobretudo pelas elevadas precipitações pluviométricas, associadas ao assoreamento progressivo das lagunas e canais, agravados pelo desenvolvimento urbano das regiões do entorno, estimulado pelas pequenas declividades existentes, que reduz a capacidade de acumulação e regulação natural destes alagados.

O local representa uma das principais vertentes de crescimento da cidade. 0 cenário urbano desta área é diversificado, contendo localidades com altos índices de urbanização na cidade, como a Barra da Tijuca e Taquara, e locais de características peri-urbanas, tais como Vargem Grande e Vargem Pequena. Entretanto, o processo de urbanização vem se desenvolvendo de forma intensa sobre estes locais, tornando-se ainda maior após o aparelhamento para realização dos Jogos Olímpicos de 2016.

No contexto deste processo de urbanização, a cidade cresce em seu aspecto formal e informal, sem respeitar os princípios norteadores do desenvolvimento sustentável. Desta forma, bairros como Vargem Grande e Vargem Pequena assistem ao avanço da implantação de condomínios fechados de uso residencial da classe média e adensamento de assentamentos informais de baixa renda, caracterizando ocupações subnormais.

As primeiras informações sobre Jacarepaguá constantes na literatura datam de 1594 . 0 desenvolvimento da região se deu primeiramente pelas atividades agropecuárias, canaviais e criação de gado, e depois o café nas partes mais elevadas. Dentre as primeiras grandes propriedades do local destacam-se as fazendas de Vargem Grande e Vargem Pequena, região onde se insere a bacia hidrográfica representativa, objeto de estudo da pesquisa. Os engenhos de senhores e ordens religiosas foram padrões de ocupação da região. A produção agropecuária foi explorada por longos períodos pela Ordem dos Beneditinos com recursos revertidos para o atual Mosteiro de São Bento, localizado no Centro do Rio de Janeiro. Aos poucos, foram sendo abertos caminhos e vias de acesso a Região, que é separada de forma marcante do restante da cidade por maciços rochosos. 
A ocupação se desenvolveu de forma gradativa. Somente a partir de 1922 foi iniciado o processo de regularização fundiária de Jacarepaguá. Nos anos de 1930, com a consolidação de vias de acesso e outras intervenções locais como canalização de rios, aterramentos, e outras obras de drenagem, foram sendo ampliados os terrenos pela drenagem das áreas antes alagadiças. Assim, foram abertas as possibilidades para a horticultura, comercializada nas partes mais centrais da cidade, e que marcou o passado mais recente da Região. A paisagem natural favoreceu também, em certo período, a implantação na Região de Casas de Repouso, Sanatórios e Retiros.

Mas, foi somente a partir da década de 1970, após o Plano Lúcio Costa, e com a abertura gradativa de túneis, que a ocupação urbana se desenvolveu de forma mais marcante. Depois da valorização imobiliária de áreas como o Bairro da Barra da Tijuca, à beira mar, com a consolidação das praias, é que se deu o adensamento da Região. No entanto, as partes mais distantes da região central do Rio, bairros da Curicica, Camorim, Vargens, onde inicialmente foram implantados Laboratórios Químicos em uma das vertentes do desenvolvimento da Região, ainda permanecem com paisagem periurbana.

Atualmente, a Região da Baixada de Jacarepaguá é denominada como Área de Planejamento 4 (AP 4) pela Prefeitura da Cidade. A bacia representativa do Rio Morto, objeto de estudo, foi estabelecida no Bairro de Vargem Grande, que tem paisagem periurbana. Os limites da bacia estão compreendidos entre as coordenadas $43^{\circ} 29^{\prime} 43^{\prime \prime}$ e $43^{\circ} 27^{\prime} 10^{\prime \prime}$ de longitude oeste e $22^{\circ} 56^{\prime} 43^{\prime \prime}$ e $22^{\circ} 59^{\prime} 10^{\prime \prime}$ de latitude sul. 0 exutório da bacia coincide com o local onde antes havia um posto fluviométrico para medição de vazões operado pelo Estado. A bacia compreende uma área de aproximadamente 9 $\mathrm{km}^{2}$. A Figura 3 destaca a localização e a delimitação da bacia hidrográfica do rio Morto na AP 4 .

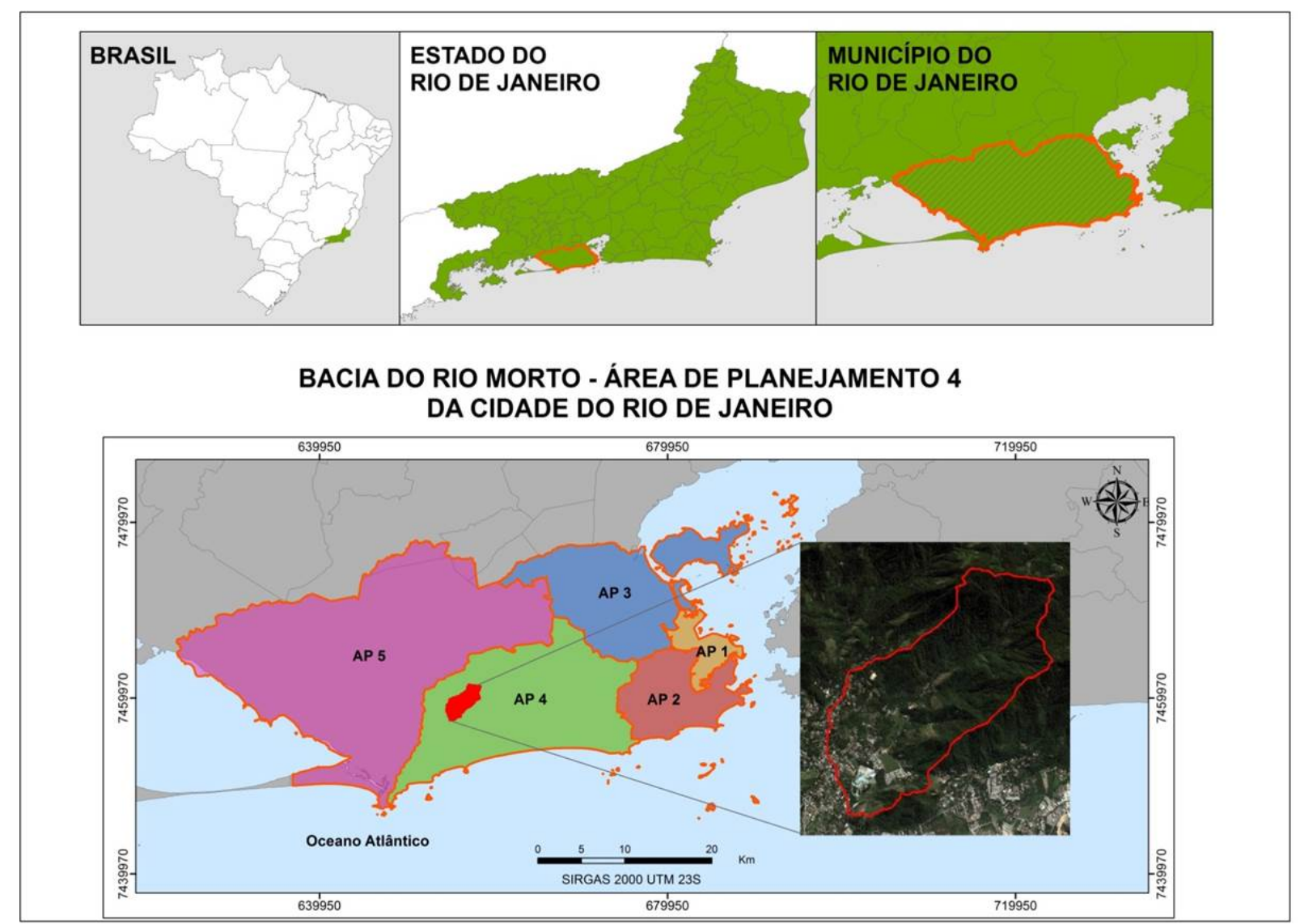

Figura 3. Localização da bacia hidrográfica do rio Morto. Fonte: Elaborado com base em Amaral (2014) e no Portal Geo-Rio (2016).

A parte mais alta da bacia encontra-se dentro dos limites do Parque Estadual da Pedra Branca, Área de Preservação Permanente (APP) com vegetação típica de Mata Atlântica. 0 restante da bacia localiza-se nos trechos médio e baixo do rio Sacarrão, principal afluente do rio Morto, onde na atualidade se verifica a presença de condomínios residenciais, pequenos comércios e assentamentos informais. 
Ao longo dos últimos anos, como em outros locais em Jacarepaguá, a ocupação da bacia tem se tornado mais significativa. Entretanto, o processo de urbanização não tem sido acompanhado da execução de planejamento territorial-urbano adequado, já que as ocupações irregulares não puderam ser contidas, não foi até a presente data construída rede de drenagem de águas pluviais, e nem todas as edificações estão ligadas à rede de esgotamento sanitário existente. Além do lançamento de esgotos, muitas vezes sem nenhum tratamento prévio, contribuem para a degradação dos corpos hídricos locais, sobretudo nos trechos médio e baixo da bacia, o lançamento de outros efluentes e entulhos, assim como a remoção da mata ciliar e ocupação das regiões ripárias (Pimentel da Silva et al., 2008). As maiores enchentes registradas na região ocorreram em 1996, 2010 e 2012. A magnitude destas inundações se deu pela associação de eventos pluviométricos intensos e estágio de maré alta. Os efeitos destrutivos foram severos como, por exemplo, prejuízo econômico, desalojamento de inúmeras famílias e até mesmo perda de vidas.

Dentro do contexto do Projeto HIDROCIDADES (Pimentel da Silva et al., 2008), diversos monitoramentos foram realizados na bacia como, por exemplo, levantamento de seções topobatimétricas e dados topográficos, obtenção de parâmetros físico-hídricos do solo e qualidade das águas, dados de uso e ocupação do solo, além do registro de dados hidro-climatológicos através de duas estações fluviométricas e duas climatológicas (dados monitorados: alturas pluviométricas, temperaturas médias, radiação solar, velocidade dos ventos, direção dos ventos, umidade relativa e pressão atmosférica) localizadas próximo do exutório da bacia, com dados registrados a cada 5 minutos, no período de 2008 a 2016.

\subsection{Modelo hidrológico-hidráulico SWMM}

O modelo hidrológico SWMM foi desenvolvido pela primeira vez em 1971 pela US-EPA e desde então vem sofrendo diversas atualizações, sendo a Versão 5.1 a mais atual (Rossman, 2015). Este programa computacional é de domínio público e tem seu código de programação aberto, o que possibilitou, por exemplo, sua integração com o ambiente SIG e CAD. Neste trabalho foi aplicada a Versão 5.1.010, que corresponde a uma extensão da versão 5.1.

O SWMM inclui um modelo chuva-vazão, que é capaz de simular a quantidade e qualidade do escoamento superficial de um único evento chuvoso ou de forma contínua, a longo prazo, em bacias especialmente urbanas. Entretanto, foram sendo agregados desenvolvimentos na estrutura original do modelo que possibilitou a aplicação do mesmo à bacias peri-urbanas. Bastos (2007) destaca que o modelo apresenta-se como ferramenta importante para o gerenciamento e planejamento da drenagem pluvial também em bacias rurais e peri-urbanas.

De forma abrangente, estes modelos constituem softwares computacionais que representam conceitualmente as principais etapas da fase terrestre do ciclo hidrológico através de um sistema de equações matemáticas de base física: taxas de infiltração, armazenamento e escoamentos. Os dados de entrada típicos desses modelos são séries temporais pluviométricas, taxas evapotransporimétricas, e vazões observadas, sendo que estas últimas permitem o ajuste dos parâmetros que caracterizam aspectos físicos da bacia, que por ventura não se tenha uma avaliação precisa de seu valor. No modelo SWMM também são incorporados e consideradas informações a respeito do uso e ocupação dos solos, além da forma das seções transversais de escoamento dos rios e canais hidráulicos. Huber \& Dickinson (1992) apresentam uma visão geral da estrutura do modelo SWMM, que é composta por seis módulos de serviço, quatro módulos computacionais, e um módulo executivo, conforme mostra a Figura 4. Dentre os módulos computacionais, foram utilizados neste trabalho o módulo Chuva-vazão (Runoff), responsável pela geração do escoamento superficial e subsuperficial com base na definição de um hidrograma, condições antecedentes de umidade do solo, uso do solo e topografia, o módulo Transporte nos Condutos (Extran), que trata da propagação dos escoamentos nos condutos e canais, e o módulo Armazenamento/ Tratamento (Storage/Treatment), que caracteriza os efeitos dos dispositivos de controle da vazão e qualidade da água.

A Versão 5.1.010 do SWMM possibilita representar o desempenho hidrológico dos dispositivos de desenvolvimento de baixo impacto. 0 usuário tem a opção de escolher oito tipos diferentes de dispositivos para representar na área de estudo: células de biorretenção, jardins de chuva, 
telhados verdes, trincheiras de infiltração, pavimento permeável, barris de chuva (ou cisternas), calhas e células vegetativas (Rossman, 2015).

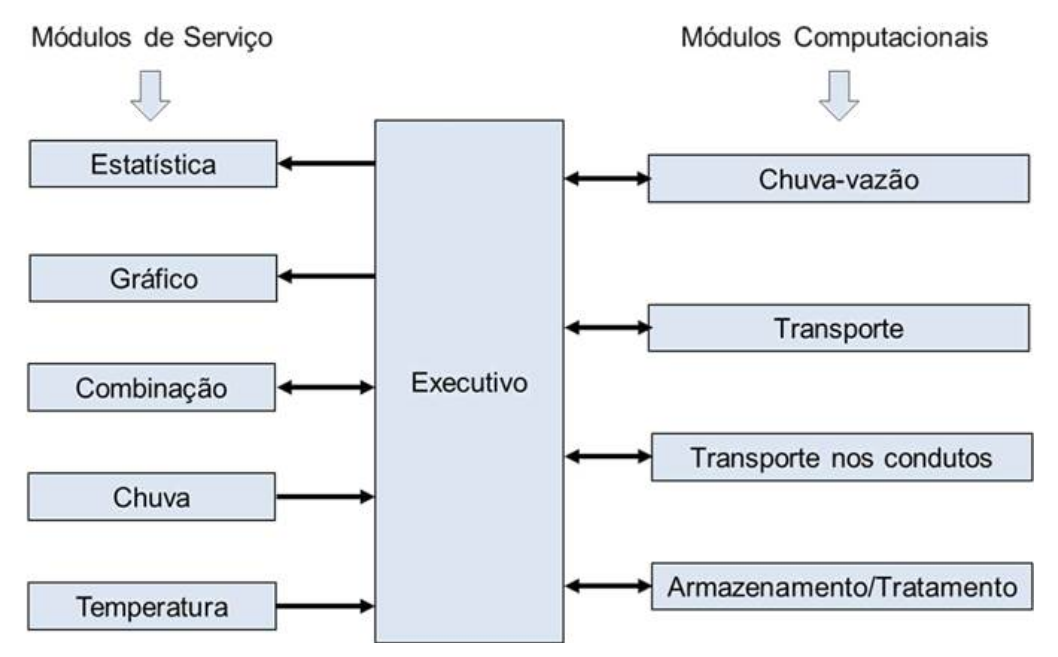

Figura 4. Relação entre os módulos do SWMM Fonte: Adaptado de Huber \& Dickinson (1992).

No SWMM, a representação da estrutura do telhado verde é composta por três camadas: superfície, solo e drenagem. Para cada camada torna-se necessário a definição de parâmetros específicos. Em relação à superfície, os parâmetros são: profundidade de armazenamento, fração do volume de vegetação, coeficiente de rugosidade de Manning e declividade do telhado. Os parâmetros que definem o solo são: espessura, porosidade, capacidade de campo, ponto de murcha, condutividade hidráulica, gradiente da curva de condutividade hidráulica e sucção capilar. 0 sistema de drenagem é caracterizado pela espessura da camada drenante, fração de vazios e coeficiente de rugosidade de Manning. A Figura 5 apresenta a janela de edição para definição e caracterização dos telhados verdes a serem simulados no modelo computacional.

\subsection{Aplicação do Modelo SWMM na Bacia do Rio Morto}

\subsubsection{Discretização da bacia do rio Morto}

A aplicação do modelo SWMM envolve a divisão da bacia hidrográfica em áreas homogêneas, denominadas sub-bacias ou elementos de drenagem. A bacia do rio Morto foi dividida em 43 subbacias, de acordo com a topografia da região, consolidada a partir de Amaral (2014). Neste trabalho foi realizada uma nova subdivisão considerando, além da lógica topográfica e a topologia da rede de drenagem, as características de uso e ocupação do solo. Esta nova discretização foi motivada, sobretudo, pelos objetivos do estudo em analisar cenários com implementação de telhados verdes nas edificações, de forma a verificar o impacto na forma do hidrograma de vazões e no controle de enchentes.

\subsubsection{Calibração e Validação dos Parâmetros do SWMM}

O ajuste dos parâmetros do modelo SWMM envolve a identificação do conjunto de parâmetros que resultará na melhor aproximação entre valores observados e estimados pelo modelo para as vazões no ponto de controle, no exutório da bacia hidrográfica. Neste trabalho, o ajuste dos parâmetros do escoamento superficial e subterrâneo da bacia do rio Morto foi feito a partir da série histórica de vazões observadas para os eventos pluviométricos de dezembro de 2008 e junho de 2010. A calibração foi feita pelo método da tentativa e erro. Os valores atribuídos aos parâmetros do SWMM para a bacia do rio Morto em Amaral (2014) serviram como ponto de partida na calibração dos parâmetros. Foram também considerados os valores atribuídos aos parâmetros em outras aplicações do SWMM em bacias hidrográficas brasileiras (Nunes et al., 2015).

Com os parâmetros ajustados, a validação consiste na realização de uma nova simulação com novos dados de entrada, sem promoção de outros ajustes, verificando a qualidade e eficiência do 
processo de calibração. Além da observação visual de ajuste entre os hidrogramas de vazões simuladas e observadas em medições in situ, são considerados também parâmetros estatísticos que inferem a aproximação entre estes hidrogramas. A validação do modelo SWMM foi feita para o evento pluviométrico observado de abril de 2010.

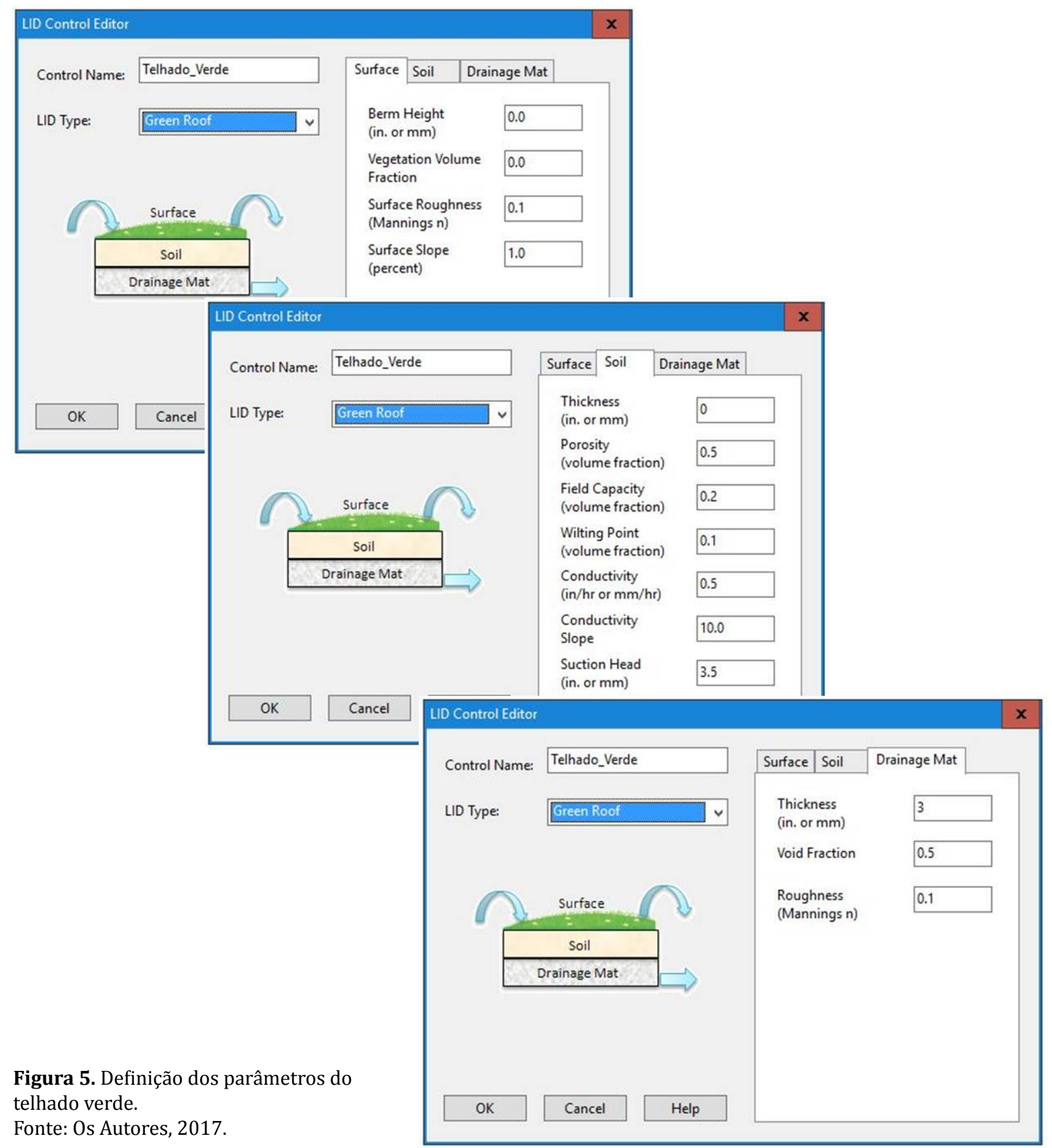

\subsubsection{Cenários com inserção de telhados verdes estudados no SWMM para a Bacia do Rio Morto}

Os cenários estudados no SWMM para a bacia do rio Morto consideram a situação atual da bacia e a implantação de telhados verdes nas áreas que concentram um maior número de edificações. 0 evento pluviométrico considerado nas simulações refere-se à Abril de 2010, caracterizado pela ocorrência de cheia emblemática na região.

A inserção hipotética de telhados verdes foi considerada na parte mais baixa da bacia, onde verifica-se um processo crescente de urbanização com presença significativa de condomínios residenciais e assentos informais. A Figura 6 destaca os elementos de drenagem que foram considerados neste cenário: sub-bacias de número 36, 37 e 43. 


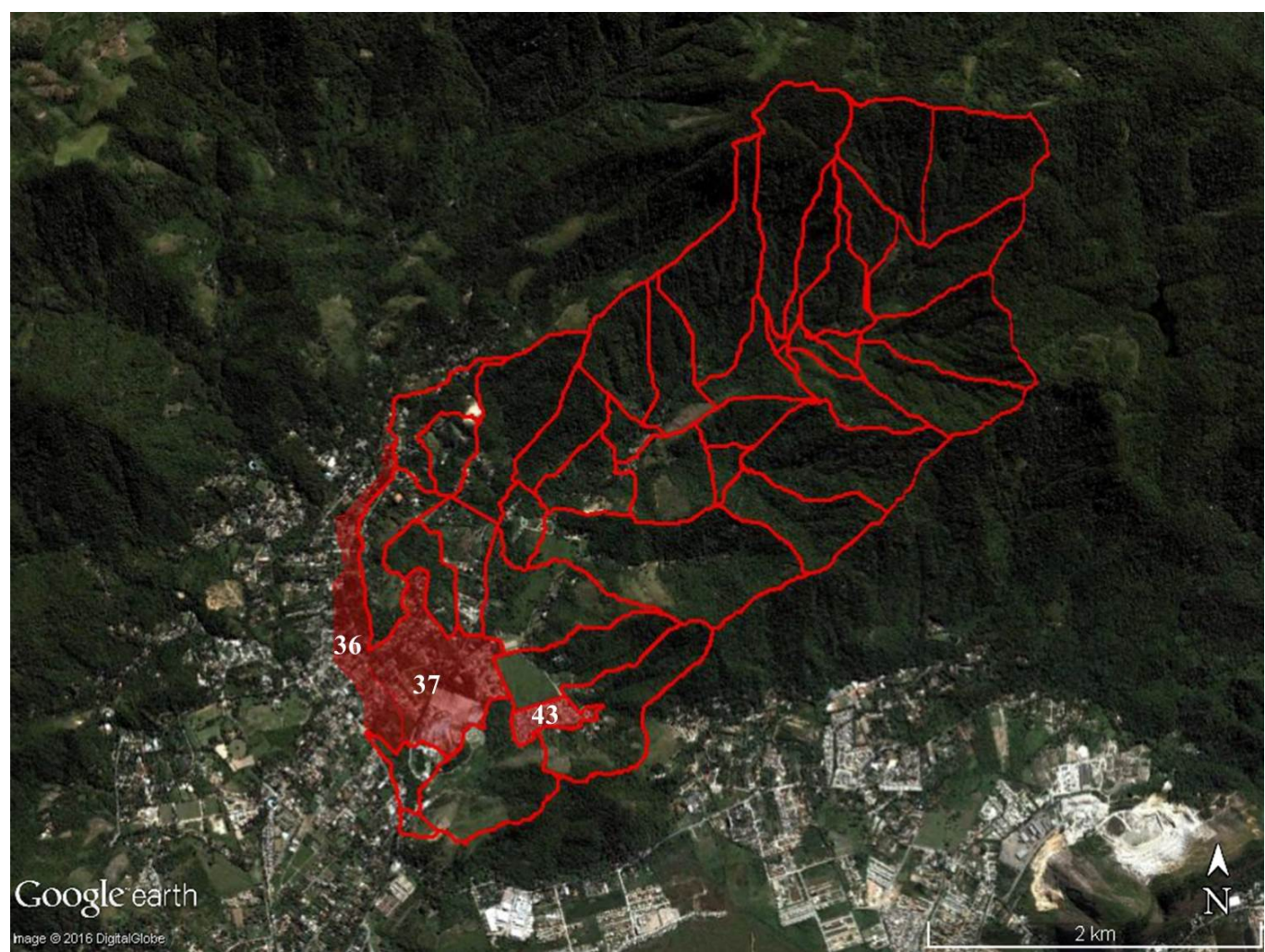

Figura 6. Destaque para as sub-bacias 36, 37 e 43, consideradas no cenário com implantação de telhado verde. Fonte: Os Autores, 2017.

Em todos os casos, considerou-se a implantação de telhados verdes em 100\% das áreas de telhado contabilizadas em cada sub-bacia, para efeitos de simulação virtual no modelo computacional hidrológico-hidráulico. Na Tabela 1 são apresentadas as áreas totais de cada um desses elementos e as áreas de telhados de edificações, que foram substituídas pela cobertura com vegetação.

Tabela 1. Área de telhado verde considerada em cada sub-bacia para simulação no modelo SWMM.

\begin{tabular}{|c|c|c|c|}
\hline Sub-bacia & Área total $\left(\mathbf{m}^{\mathbf{2}}\right)$ & $\begin{array}{c}\text { Área de Telhado } \mathbf{2} \\
\text { Telhado Verde }\left(\mathbf{m}^{\mathbf{2}} \mathbf{)}\right.\end{array}$ & \% de Telhado Verde \\
\hline 36 & 273800 & 54760.00 & 20 \\
\hline 37 & 475859 & 118964.75 & 25 \\
\hline 43 & 74711 & 37355.50 & 50 \\
\hline
\end{tabular}

Fonte: Os Autores, 2017.

Observa-se que o elemento/sub-bacia "43" é o que apresenta maior taxa de ocupação com edificações, mas também é o menor em extensão em relação aos outros. Veja na Figura 6. Este elemento corresponde à área de ocupação de assentamento informal.

A definição dos parâmetros de cada camada do telhado verde utilizado nas simulações teve como referência os trabalhos desenvolvidos por Loiola (2015), Garrido Neto (2016), Jato-Espino et al. (2016) e Krebs et al. (2015). Também foram utilizados os valores de referência apresentados no manual do SWMM (Rossman, 2015).

A Tabela 2 consolida os parâmetros definidos para o telhado verde típico considerado nas simulações do modelo SWMM. Foi considerado, hipoteticamente, que o solo apresenta textura francoarenosa. A declividade do telhado verde foi atribuída àquela típica dos telhados encontrados nas edificações existentes nas edificações do local. 
Tabela 2. Valores dos parâmetros do telhado verde considerados nas simulações do modelo SWMM.

\begin{tabular}{|l|c|}
\hline \multicolumn{2}{|c|}{ Superfície } \\
\hline Profundidade de armazenamento (mm) & 75 \\
\hline Fração do volume de vegetação & 0.1 \\
\hline Coeficiente de rugosidade de Manning & 0.24 \\
\hline Declividade do telhado (\%) & 6 \\
\hline Espessura (mm) & 150 \\
\hline Porosidade (fração de volume) & 0.45 \\
\hline Capacidade de campo (fração de volume) & 0.19 \\
\hline Ponto de murcha (fração de volume) & 0.085 \\
\hline Condutividade hidráulica (mm/h) & 11 \\
\hline Gradiente da Curva de condutividade & 10 \\
\hline Sucção capilar (mm) & 110 \\
\hline Fração de vazios & 0.6 \\
\hline Coeficiente de rugosidade de Manning & 0.4 \\
\hline
\end{tabular}

Fonte: Os Autores, 2017.

A Figura 7 apresenta um esquema simplificado do telhado verde considerado nas simulações computacionais utilizando o modelo SWMM. A textura terá impacto no armazenamento de água no substrato e na redução do escoamento superficial, já que a textura está diretamente relacionada com a capacidade de retenção e com a condutividade hidráulica dos solos. A textura arenosa corresponde aos solos com maior condutividade e menores capacidades de retenção. As texturas argilosas se posicionam exatamentente no extremo oposto. Os solos franco-arenosos possuem uma granulometria (ou diâmetro dos grãos) que compõem a posição intermediária da matriz do solo, que é compatível com solos adequados ao cultivo.

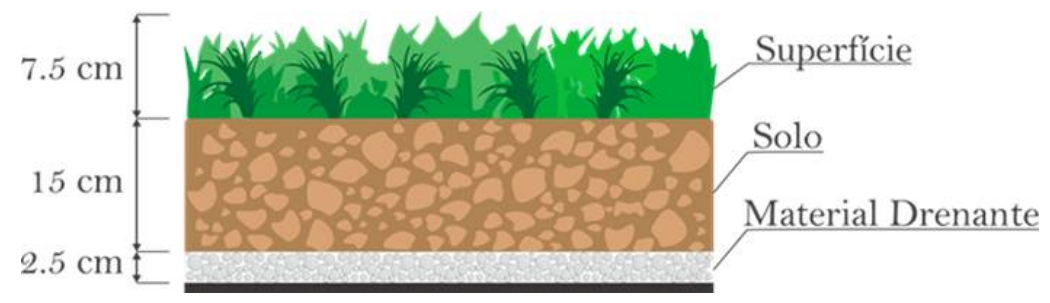

Figura 7. Esquema representativo do telhado verde considerado nas simulações do modelo SWMM. Fonte: Os Autores, 2017.

\section{Discussão e avaliação dos resultados do papel dos telhados verdes no DDUBI e no controle de enchentes}

Os telhados verdes caracterizam-se como elementos transversais no desenho e desenvolvimento urbano de baixo impacto ambiental, já que contribuem em diferentes aspectos: como elemento no paisagismo; aumentam a sensação de bem estar pela proximidade do verde; absorção de $\mathrm{CO}_{2}$, 
contribuindo para a diminuição dos efeitos das ilhas de calor e estufa; aumentam o conforto ambiental interno das edificações; com a diminuição do consumo de energia para climatização; controle da poluição sonora; espaço para agricultura urbana com todos os seus rebatimentos (ratificação do senso de comunidade e solidariedade, produção de alimento, diminuição da distância entre produtor e consumidor, controle do preço e inflação de produtos agrícolas, diminuição do consumo de combustível para o transporte dos alimentos das regiões rurais para a cidade, redução da queima de combustíveis fósseis e redução dos gases do efeito estufa); aproveitamento de materiais vegetais residuais como substrato agrícola; geração de emprego, aumento da renda e da cidadania; recomposição dos ecossistemas naturais anteriores à urbanização; aproveitamento das águas pluviais e controle da poluição; controle dos escoamentos superficiais e das enchentes urbanas.

A vegetação da cobertura das edificações já era empregada por povos antigos como os Babilônios na forma de jardins suspensos. Mas, os telhados verdes atuais se beneficiam de novas tecnologias, de novos materiais e melhor segurança construtiva. Dessa forma, estimulam um novo mercado, sobretudo no espaço urbano dos países ainda em desenvolvimento, onde este dispositivo ainda não é de conhecimento geral, sendo pouco utilizado. Para sua ampla aplicação é necessário o surgimento de uma nova cadeia produtiva no espaço urbano.

Apesar dos ativos apresentados, os telhados verdes não são empregados amplamente, sobretudo nos países de clima tropical. 0 desempenho dos telhados verdes depende fortemente do clima, já que utiliza-se de elementos naturais no desenho urbano, como vegetação, substrato, entre outros, $\mathrm{e}$ tecnologias específicas, sobretudo materiais impermeabilizantes na superfície de cultivo, e mantas que impedem o avanço das raízes nos elementos construtivos e ambiente interno da edificação. Nas regiões de clima tropical observa-se a necessidade de ampliação da pesquisa para melhor apropriação de seus impactos positivos e concretização das barreiras para ampliação de sua aplicação nos espaços urbanos. Os telhados verdes recompõem os ecossistemas naturais e aproximam o ser humano da natureza, com seus impactos positivos, embora com alguns inconvenientes como a aproximação de insetos, pássaros e, eventualmente roedores. A saúde pode também ser impactada pelo eventual aumento da umidade no ambiente interno das edificações. 0 manejo e a manutenção do telhado vegetado pode ser oportunidade para alguns, mas trabalho extra ou aumento de custo para outros. Os procedimentos corretos e os insumos necessários, que facilitam e garantem a manutenção desses sistemas, precisam ser desenvolvidos no contexto das grandes cidades Brasileiras. Neste caso, diversas questões devem ser avaliadas e definidas, tais como: qual o melhor substrato para cultivo; quais são as vegetações mais adequadas; quais materiais podem ser reaproveitados; existe a necessidade de suprimento hídrico extra além das águas pluviais; como drenar de forma correta os efluentes desses sistemas; quais os aportes de poluentes das superfícies vegetadas; onde adquirir os materiais e mão de obra necessários; qual o impacto exato na redução do consumos de energia, água, produção de alimentos e renda (agricultura urbana), redução do escoamento superficial, e, no caso da agricultura urbana, quanto em alimentos pode ser produzido.

Aprofundando-se na questão associada à retenção das águas pluviais promovidas pelos telhados verdes e que podem contribuir para o controle das enchentes, após as simulações computacionais para as sub-bacias 36,37 e 43 , foram obtidas as respostas correspondentes em termos de vazão fluvial para o evento pluviométrico emblemático que ocorreu em abril de 2010. Nas Figuras 8, 9 e 10 são ilustrados os resultados para cada sub-bacia. Nestas figuras, as linhas tracejadas (na cor vermelha) representam as vazões ao longo do tempo com a inserção dos telhados verdes. Já as linhas contínuas (na cor azul) são as vazões ao longo do tempo, considerando a situação atual, sem a inserção dos telhados verdes. Em todos os casos, a maior vazão observada nestas sub-bacias foi reduzida para a hipótese em que foram incluídos os telhados verdes.

O mesmo foi observado para a atuação conjunta dos telhados verdes nas três sub-bacias 36,37 e 43 , se analisada a vazão de pico no hidrograma no exutório da bacia hidrográfica. No entanto, os resultados indicam que o impacto foi mais significativo na escala das sub-bacias. As simulações também apontaram que somente a inclusão dos telhados verdes não seria capaz de reverter totalmente o extravasamento das calhas fluviais. Além disso, não foi observado o retardo da vazão de pico em nenhum dos hidrogramas simulados. Verificou-se, no entanto, que para a vazão 
de pico houve uma redução de $7.8 \%, 11.1 \%$ e $4.1 \%$, nas sub-bacias 36,37 e 43 , respectivamente. Enquanto que para o volume escoado, obteve-se uma redução de $8.1 \%, 9.0 \%$ e $3.0 \%$, respectivamente. 0 cenário com a inserção de telhados verdes de forma conjunta nestas sub-bacias levou à redução da vazão de pico no exutório da bacia do rio Morto da ordem de 1.0\%.

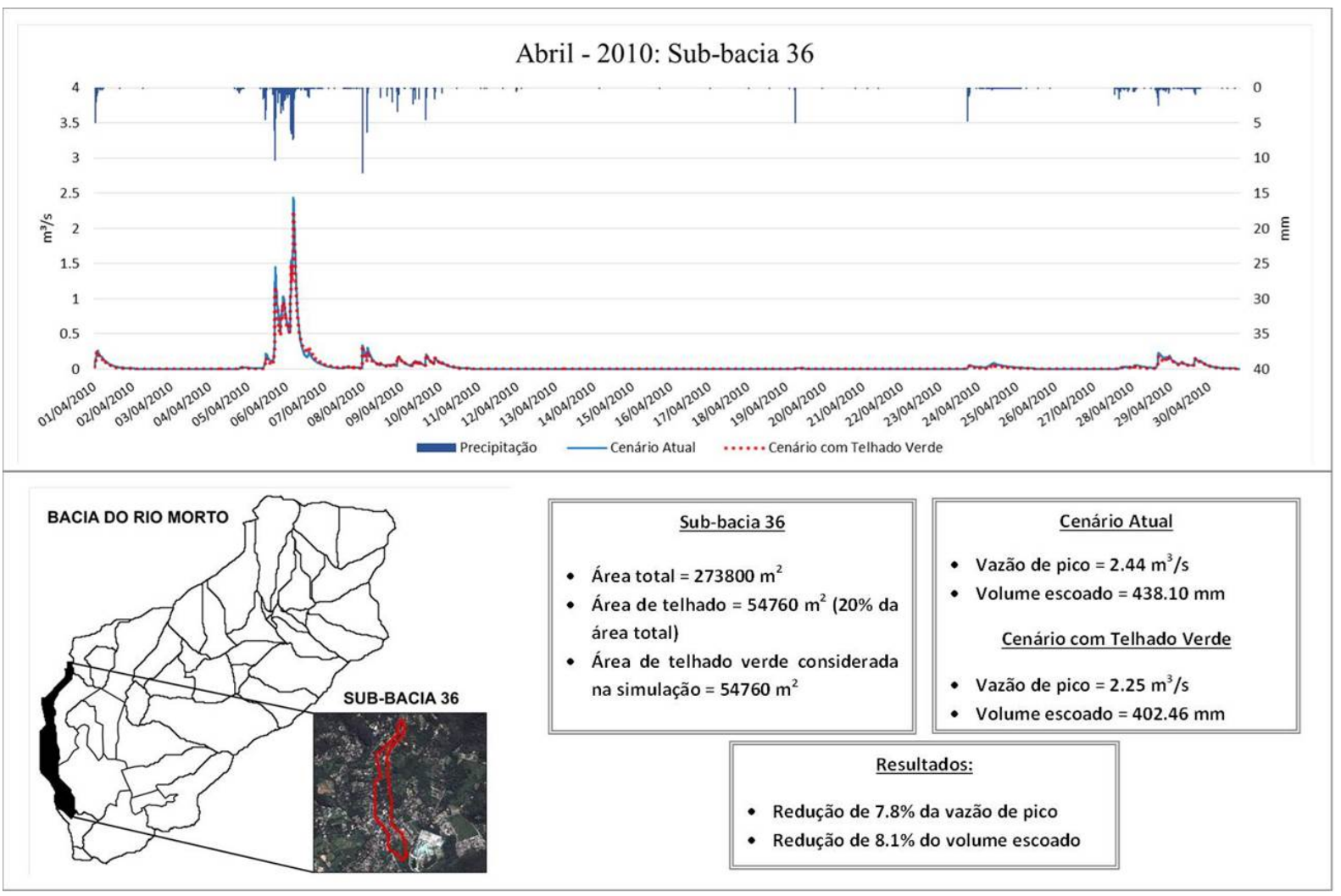

Figura 8. Hidrogramas dos cenários propostos para a sub-bacia 36. Fonte: Os Autores, 2017.

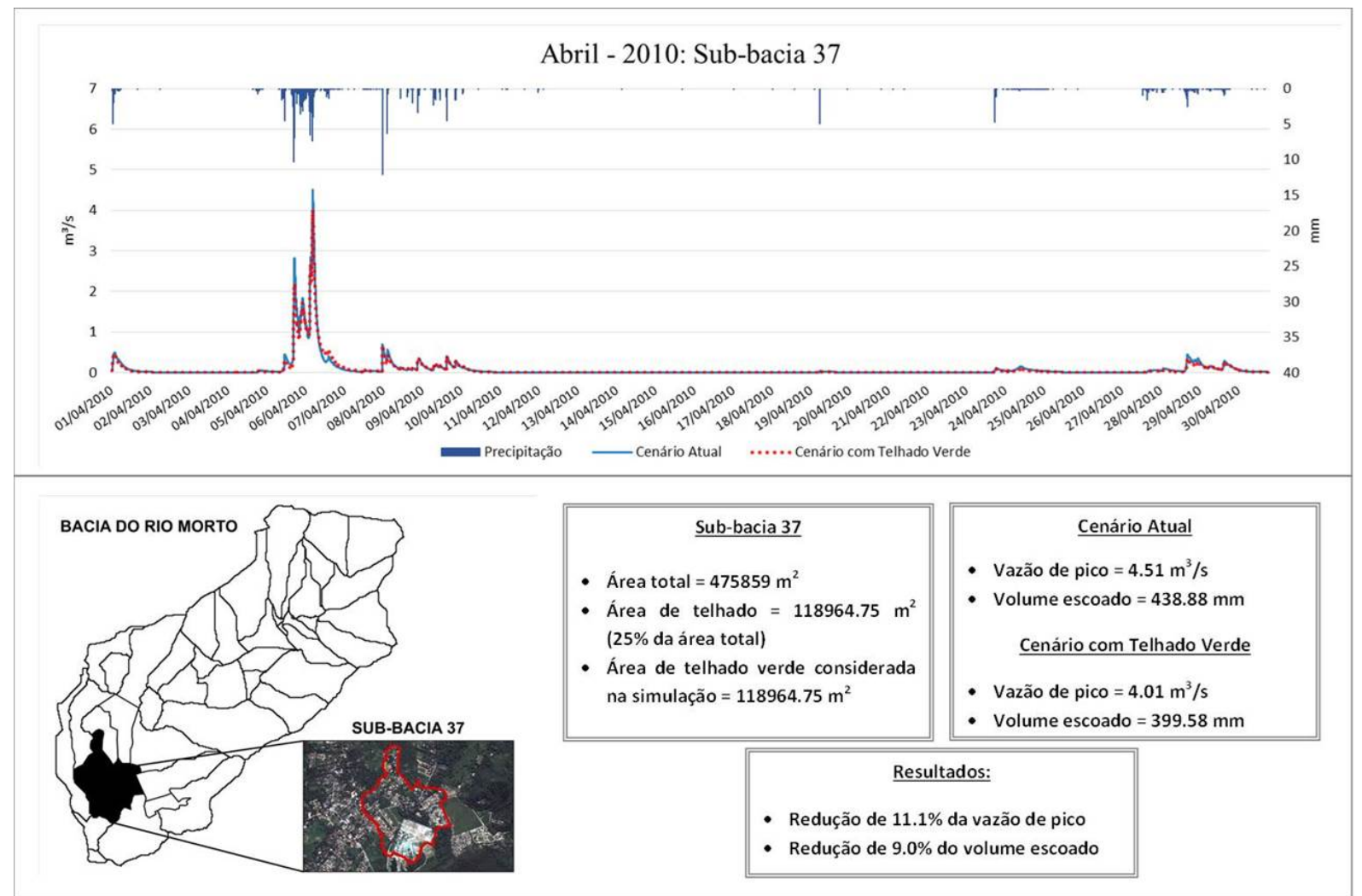

Figura 9. Hidrogramas dos cenários propostos para a sub-bacia 37. Fonte: Os Autores, 2017. 


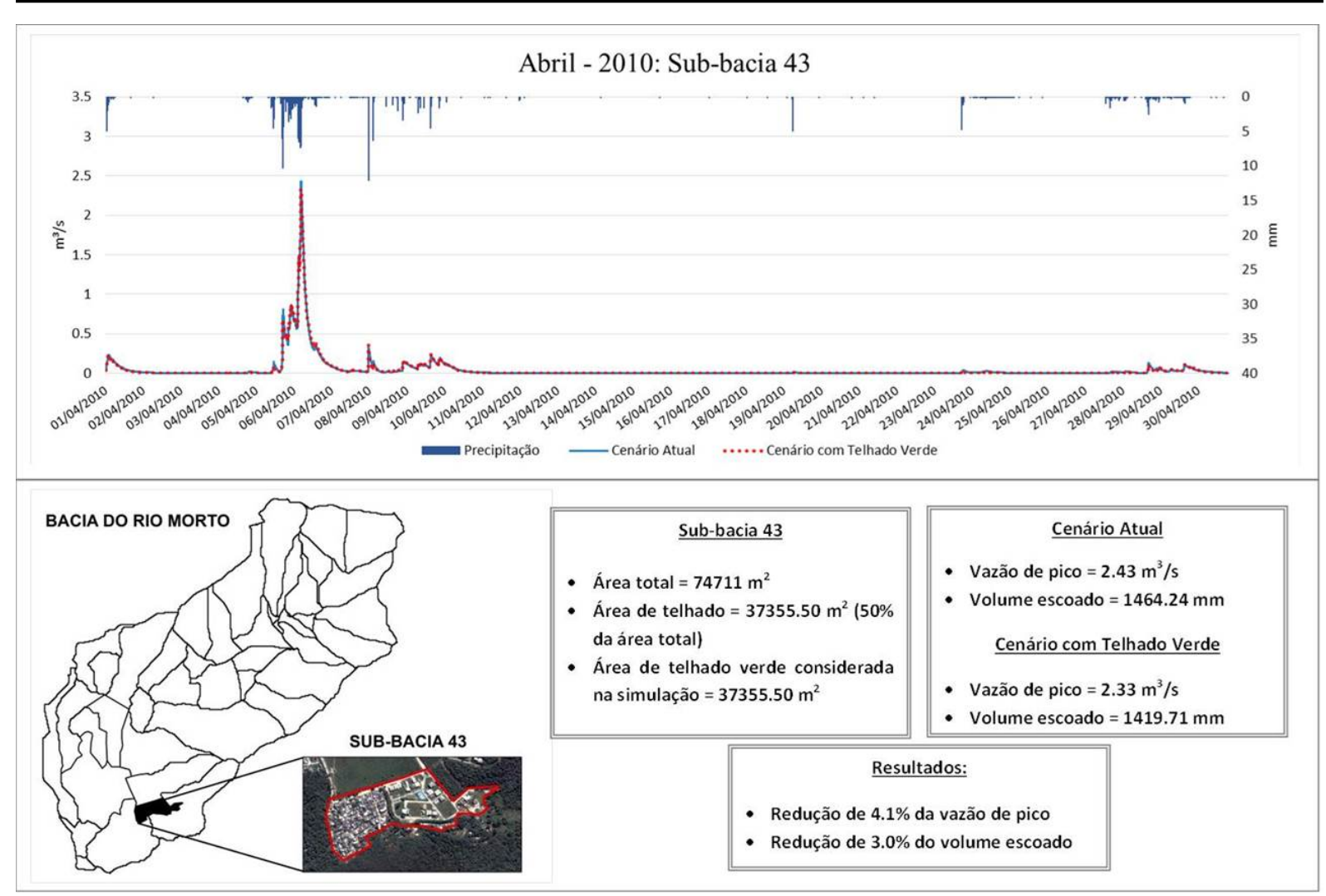

Figura 10. Hidrogramas dos cenários propostos para a sub-bacia 43. Fonte: Os Autores, 2017.

\section{Conclusões}

A análise do papel dos telhados verdes como medida transversal no DDUBI pode ratificar, a partir de elementos da literatura, os impactos positivos dos mesmos para o desenvolvimento urbano dentro dos princípios da sustentabilidade. No entanto, foi evidenciado que as pesquisas sobre os telhados verdes dependem das condições climáticas, materiais e aspectos construtivos, além de questões de ordem social e cultural.

Os estudos experimentais em unidades construtivas permitem a avaliação individual do impacto do dispositivo em suas diferentes funções. 0 aprofundamento da questão relacionada à retenção de águas pluviais e a aplicação do modelo computacional permitiu a simulação do impacto da adoção dos telhados verdes de forma agregada.

A simulação de cenários com telhados verdes na bacia hidrográfica do rio Morto foi feita individualmente para as sub-bacias 36, 37 e 43, e, posteriormente, de forma conjunta para estas subbacias. Foi verificado nos cenários estudados, para o evento observado de Abril de 2010, emblemático para a região, que se em todas as construções existentes nos elementos considerados (com maior taxa de ocupação) fossem implementados telhados verdes, somente este dispositivo não seria capaz de evitar todos os transbordamentos das calhas fluviais que foram observados na época. No entanto, foi verificado que poderia obter-se uma redução de pelo menos $4 \%$ nas vazões máximas e de $3 \%$ nos volumes escoados, considerando a escala das sub-bacias. Observou-se também que não houve retardo no tempo de ocorrência da vazão máxima e que o impacto é maior na escala das sub-bacias, sendo seu efeito amortecido no hidrograma total. Cabe ressaltar que o impacto da implantação de telhados verdes na redução do escoamento superficial local teria benefícios significativos para a população residentes nas áreas mais densamente ocupadas, sobretudo em espaços subnormais que não contam com redes de infraestrutura urbana.

Dado o impacto transversal dos telhados verdes e o observado nos hidrogramas nas simulações virtuais com cenários de telhados verdes na bacia do rio Morto, que não é ainda tão urbanizada, entende-se que estes dispositivos podem ter impacto ainda mais relevante em bacias densamente urbanizadas. Sugere-se ainda, que sejam feitas análises no futuro considerando outras 
configurações de telhados verdes e integrando na bacia de estudo outros dispositivos de drenagem do DDUBI.

\section{Referências}

Amaral, D. P. B. (2014). Aplicação do modelo hidrológico SWMM na gestão das águas pluviais urbanas: estudo de caso da bacia hidrográfica do Rio Morto. (Dissertação de Mestrado) - Faculdade de Engenharia, Universidade do Estado do Rio de Janeiro, Rio de Janeiro, RJ, Brasil.

AMEC. (2001). Georgia Stormwater Management Manual, Volume 2: Technical Handbook. AMEC Earth and Environmental, Center for Watershed Protection, Atlanta - USA.

Baptista, M. et al. (2005). Técnicas compensatórias em drenagem urbana. Porto Alegre: ABRH.

Barlow, D. et. al. (1977). Research report on developing a community level natural resource inventory system: Center for Studies in Food Self-Sufficiency.

Bastos, G. A. P. (2007). Análise dos parâmetros do modelo SWMM para avaliação do escoamento em duas bacias periurbanas em Santa Maria-RS. (Dissertação de Mestrado) - Centro de Tecnologia, Universidade Federal de Santa Maria, Rio Grande do Sul, RS, Brasil.

Berardi, U., Ghaffarianhoseini, A., \& Ghaffarianhoseini, A. (2014). State-of-the-art analysis of the environmental benefits of Green roofs. Apllied Energy, (115), 411-428.

Berndtsson, J. C. (2010). Green roof performance towards management of runoff water quantity and quality: A review. Ecological Engineering, 36 (4), 351-360.

Bianchini, F., \& Hewage, K. (2012). How green are the green roof? Lifecycle analysis of green roof materials. Building and Environment, (48), 57-65.

Bracey, S. et al. (2008). Lessons Applying Low-Impact Urban Design: Talbot Park. In: Stormwater Conference, Oakland.

Canero, R. F., \& Redondo, P. G. (2010). Green Roof as a Habitat for Birds: A Review. Journal of Animal and Veterinary Advances, 9 (15), 2041-2052.

Carter, T., \& Butler, C. (2008). Ecological impacts of replacing traditional roofs with green roofs in two urban areas. Cities and the Environment, 1 (2), 1-17.

Cerqueira, L. F. F. (2012). Redesenho Urbanístico de Assentamentos Informais com Vistas à Conservação da Água e Sustentabilidade Ambiental. (Tese de Doutorado). Universidade do Estado do Rio de Janeiro, Rio de Janeiro, RJ, Brasil.

Cerqueira, L. F. F., \& Pimentel da Silva, L. (2013). Política habitacional brasileira, proliferação de assentamentos informais, recursos hídricos e sustentabilidade urbana na cidade do Rio de Janeiro. Revista Labor \& Engenho, $7(2), 26-44$.

Cerqueira, L. F. F., \& Pimentel da Silva, L. (2016). Methodological Proposal for Redesigning Informal Communities - Constructing Resilience in Hydrological Stress Conditions. Ambiente \& Sociedade (Online), 19 (1), 43-62.

Chatfield, P. (2005). SUDS - Benefits to be gained from a strategic approach. In SUDS - Time to Get to Grips With It, London, United Kingdom.

Coffman, L. S. (2002). Low-impact Development: An Alternative StormwaterManagement Technology. In France, R. L., (Org.). Handbook of Water Sensitive Planning and Design. Massachussets, USA: ed. Lewis Publishers, chapter. I.05, 97-124. 
Fletcher, T. D. et al. (2014). SUDS, LID, BMPs, WSUD and more - The evolution and application of terminology surrounding urban drainage. Urban Water Journal, 12 (7), 525-542.

Garrido Neto, P. S. (2016). Telhados verdes como técnica compensatória em drenagem urbana na cidade do Rio de Janeiro: Estudo experimental e avaliação de sua adoção na bacia do rio Joana a partir do uso de modelagem matemática. (Dissertação de Mestrado) - Instituto Alberto Luiz Coimbra de Pós-graduação e Pesquisa de Engenharia (COPPE), Universidade Federal do Rio de Janeiro, Rio de Janeiro, RJ, Brasil.

Getter, K. L., \& Rowe, D. B. (2006). The Role of Extensive Green Roofs in Sustainable Development. Horts Science, 41 (5), 1276-1285.

Hall, M. J. (1984). Urban Hydrology. Belfast: The Universities Press, Elsevier Applied Science Publishers Ltd.

Huber, W. C., \& Dickinson, R. E. (1992). Storm Water Management Model, Version 4: User's Manual. Athens, Georgia : U.S. Environmental Protection Agency.

Jato-Espino, D. et al. (2016). Rainfall-Runoff Simulations to Assess the Potential of SuDS for Mitigating Flooding in Highly Urbanized Catchments. International Journal of Environmental Research and Public Health, 13( 2), 1-13.

Krebs, G. et al. (2015). Simulation of green roof test bed runoff. Hydrological Processes, 1-13.

Krüger, C. M., \& Dziedzic, M. (2010). Drenagem Urbana. Prefeitura Municipal de Curitiba, Instituto Municipal de Administração Pública/IMAP. Plano de Desenvolvimento de Competências.

Lloyd, S. (2003). Clearwater project: community acceptance of water sensitive urban design. In: Seminar of the Australian Water Association and the Stormwater Industry Association of Victoria. Managing the Changing Colours of Water, Melbourne: WIA.

Loiola, C. M. (2015). Relação chuva-vazão nos telhados verdes modulares sob chuva simulada induzida. (Dissertação de Mestrado) - Faculdade de Engenharia, Universidade do Estado do Rio de Janeiro, Rio de Janeiro, RJ, Brasil.

Loiola, C. M. et al. (2015). Caracterização do runoff em telhados verdes modulares sob chuva simulada induzida. In: XXI Simpósio Brasileiro de Recursos Hídricos, Brasília, Distrito Federal.

Mary, W. et al. (2008). Telhados Verdes: ferramenta potencial para geração de renda em área de fragilidade social. In IX Encontro Nacional de Ensino de Paisagismo em Escolas de Arquitetura e Urbanismo no Brasil. Curitiba, PR, Brasil.

Mary, W. et al. (2010). Tecnologias alternativas de produção vegetal em telhados verdes em áreas de interesse social. Revista Conexão UEPG, 6 (1), 60-67.

Ministério das Cidades. (2005). Gestão do Território e Manejo Integrado das Águas Urbanas. Cooperação Brasil-Itália em Saneamento Ambiental. Brasília: Secretaria Nacional de Saneamento Ambiental.

Nunes, D. M. et al. (2015). Análise dos parâmetros ajustados para o modelo hidrológico SWMM para bacias hidrográficas brasileiras. In XXI Simpósio Brasileiro de Recursos Hídricos, Brasília, Distrito Federal.

Oliveira, E. W. N. de. (2009). Telhados verdes para habitações de interesse social: retenção das águas pluviais e conforto térmico. (Dissertação de Mestrado) - Faculdade de Engenharia, Universidade do Estado do Rio de Janeiro, Rio de Janeiro, RJ, Brasil.

Oliveira, E. W. N. de. et al. (2009). Telhados verdes em habitações de interesse social e retenção das águas pluviais para drenagem urbana sustentável. In XVIII Simpósio Brasileiro de Recursos Hídricos, Campo Grande.

Pimentel da Silva, L. (2015). Hidrologia: Engenharia e Meio Ambiente, 1a edição, Elsevier, ISBN 978-85-352-7734-0, Rio de Janeiro, RJ, Brasil. 
Pimentel da Silva, L. et al. (2008). HIDROCIDADES - Cities, Quality of Life and Water Resources: Integrated Water Resources Management and Urban Planning for Low-Land Region of Jacarepaguá, Rio de Janeiro, Brazil. In: International Congress on Urban Drainage, Edinburgh, 11th ICUD.

Poleto, C. (2011). SUDS (Sustainable Urban Drainage Systems): Uma Contextualização Histórica. Revista Thema, 8 (1), 1-12. Porto Alegre: Ed. Instituto Federal de Educação, Ciência e Tecnologia Sul-Rio-Grandense.

Portal Geo-Rio. (2016). Armazém de Dados. Mapa Digital do Rio de Janeiro. Base Geoweb - Extração de Base de Dados Geográficos. Recuperado de: <http://portalgeo.rio.rj.gov.br/mapa_digital_rio/?config=config/ipp/ basegeoweb.xml>.

Rosa, E. U. (2002). Desenvolvimento de Procedimentos Computacionais para Integração de Sistemas de Informação Geográfica com Modelo Hidrológico Chuva-Vazão em Bacias Urbanas. (Dissertação de Mestrado) Universidade do Estado do Rio de Janeiro, Rio de Janeiro, RJ, Brasil.

Rosseti, K. A. C. et al. (2013). Abordagens sistêmicas dos efeitos da implantação de telhados vegetados. Brazilian Geographical Journal: Geosciences and Humanities research medium, 4 (1), 55-77.

Rossi, E., \& Sousa, L. M. G. (2012). Ecotécnicas de drenagem urbana: urbanização de impacto ambiental reduzido. In: Simpósio de pós-graduação em engenharia urbana, Maringá. Caderno de Resumos - SIMPGEU. Maringá: UEM, (3), 97-97.

Rossman, L. A. (2015). Storm Water Management Model - User's Manual Version 5.1. Cincinnati, OH: U. S. Environmental Protection Agency.

Rowe, D. B. (2011). Green roofs as means of pollution abatement. Environmental Pollution, (159), 2100-2110.

Van Roon, M. R. (2006). Water Localisation and Reclamation: Steps Towards Low Impact Urban Design and Development. Journal of Environmental Management, 83 (4), 437-447.

Van Roon, M. R. (2012). Wetlands in The Netherlands and New Zealand: Optimising biodiversity and carbon sequestration during urbanization. Journal of Environmental Management, 101 (30), 143-150.

Van Roon, M. R., \& Van Roon, H. (2005). Low Impact Urban Design and Development Principles for Assessment of Planning, Policy and Development Outcomes. Working Paper 051. Auckland: Centre for Urban Ecosystem Sustainability and Department of Planning, University of Auckland, 1-9. 